\title{
The role of sociodemographic factors associated with waterpipe smoking among male adolescents in western Iran: A cross-sectional study
}

\author{
Saeed Bashirian', Majid Barati', Hamid Abasi ${ }^{2}$, Manoj Sharma $^{3}$ and Manoochehr Karami ${ }^{4}$
}

\section{ABSTRACT}

INTRODUCTION Waterpipe smoking (WPS) is an increasingly popular leisure activity among young people in Iran. The purpose of this study was to identify the role of sociodemographic factors associated with WPS among male adolescents in Iran.

METHODS The study used a cross-sectional design. It included 730 high school male students (Grades 10-12) recruited through multistage random sampling conducted in 2017 in Hamadan city, western Iran. The self-administered questionnaires included information on demographic variables and behavioral risk factors related to WPS. Descriptive statistics and multinomial logistic regression modeling were conducted using SPSS.

RESULTS The student mean age, and standard deviation (SD), and age at WPS initiation were $16.41(0.84)$ and $13.31(2.43)$ years, respectively. The percentages of never, former and current WPS were $37.3 \%, 36.4 \%$ and $26.3 \%$, respectively. We found that ever cigarette smoking ( $\mathrm{OR}=5.14,95 \%$ CI: $2.56-$ 10.32 ) and WPS family ( $\mathrm{OR}=2.55,95 \%$ CI: $1.40-4.64)$ were significantly associated with former WPS. Furthermore, being 18 years, studying in technical fields, reporting ever and current smoking of cigarettes and family usage of WP were significantly associated with current WPS. Friends with WPS (OR= 0.50, 95\% CI: 0.34-0.72) however played a protective role on former WPS.

CONCLUSIONS The results indicate that the prevalence of former and current WPS was high in Hamadan city. Thus, designing and implementing interventions for increasing students', friends' and family's awareness regarding the harms of WPS and cigarette smoking are necessary to facilitate behavior change.

\begin{tabular}{l} 
AFFILIATION \\
1 Social Determinants of Health \\
Research Center, Hamadan \\
University of Medical Sciences, \\
Hamadan, Iran \\
2 Department of Public Health, \\
School of Health, Hamadan \\
University of Medical Sciences, \\
Hamadan, Iran \\
3 Behavioral \& Environmental \\
Health School of Public Health, \\
Jackson State University, Jackson, \\
United States \\
4 Research Center for Health \\
Sciences, Hamadan University of \\
Medical Sciences, Hamadan, Iran \\
CORRESPONDENCE TO \\
Hamid Abasi. Department of \\
Public Health, School of Health, \\
Hamadan University of Medical \\
Sciences, Hamadan, Iran. E-mail: \\
hamid_mehdi29@yahoo.com \\
KEYwORDS \\
male adolescents, risk factors, \\
student, water pipe smoking \\
\hline Received: 23 January 2018 \\
Revised: 12 May 2018 \\
Accepted: 24 May 2018 \\
\end{tabular}

ABBREVIATIONS WPS: waterpipe smoking, WP: waterpipe

\section{INTRODUCTION}

Waterpipe (i.e. hookah, narghile, hubble-bubble) smoking (WPS) has been an old tradition in different parts of the world ${ }^{1}$. Smoke for consumption is produced by burning wood coal situated at the top of a perforated aluminum foil below which mostly flavored tobacco blend is placed ${ }^{2}$.There are several harms associated with smoking waterpipe such as cancers, cardiovascular disease, stroke and others ${ }^{3}$. However, smoking waterpipes continues to be a common form of tobacco use in various regions of the world, particularly the Middle East. Many people, particularly in the Middle East, think that WPS is less harmful than cigarette smoking or even harmless ${ }^{4}$, but studies have shown that WPS has serious, chronic, harmful effects, particularly on the respiratory and cardiovascular systems ${ }^{5}$.

It is estimated that 100 million people, particularly 
teenagers, engage in WPS6. Since the 1990s, it has also become prevalent in the developed countries of the West ${ }^{7}$. Results from the 2010 Canadian Youth Smoking Survey ${ }^{8}$ revealed prevalence estimates of $10.1 \%$ for ever use and $4 \%$ for current use of WP among students in Grades 9-12. In a study in Iran, $9.7 \%$ of students smoked WP in the past month, of which $66.6 \%$ were male and $33.4 \%$ were female ${ }^{7}$. In another study in Iran, WPS prevalence was reported as $17.1 \%$ in male high school students ${ }^{9}$. WPS has a strong social aspect that makes it attractive and addictive to its users ${ }^{10,11}$. The results of a qualitative study showed that WPS is considered as enjoyable entertainment among friends, regardless of the health outcomes ${ }^{12}$.

Teenagers are especially attracted to the fragrance, to the pipe's nice appearance, easy accessibility, low cost, less stigma, and greater social acceptance ${ }^{7}$. There is generally a paucity of studies done on WPS in Iran, especially among high schools ${ }^{13,14}$. Increasing prevalence in Iran and associated negative sequelae warrant planning and implementing preventative approaches that are geared for adolescents in particular. It is generally well accepted that epidemiological studies identifying the determinants of risky behaviors such as WPS, should be undertaken before developing interventions ${ }^{15}$. Therefore, the purpose of this study was to estimate the prevalence of WPS and assess behavioral and social predictors of WPS among male adolescents in Iran.

\section{METHODS}

\section{Study participants}

A total of 780 participants were recruited in the study. However, only 730 participants finished the study yielding a $93.5 \%$ completion rate. Multistage random sampling from 13 schools in two sectors of Hamadan city was employed with 60 students from Grades 10-12 participating in the study from each school. This study was approved by the Ethics Committee of Hamadan University of Medical Sciences (ID: IR.UMSHA.REC.1396.21). Informed consent, after due explanation, was obtained from all participants before the commencement of the study.

\section{Measures}

The instrument was a self-report and consisted of information on demographic variables and WPSrelated behaviors. The completion of the instrument took about 15-20 minutes. The instrument was divided into two parts: 1) Demographic factors including age, grade, major, father's and mother's occupation, father's and mother's education, whether having own room and living status; 2) WPS-related behaviors including being never, former (smoked waterpipe even one or two inhalations in your life) and current (smoked waterpipe at least once in the previous month) WP smoker, age at WPS initiation, computer games (at all, low, medium, high) internet usage (at all, low, medium, high) ${ }^{15}$, experienced cigarette smoking (yes/no), current cigarette smoking (yes/no), having friends who smoke WP (yes/no), and having family members who smoke WP (yes/no).

\section{Data analysis}

Descriptive statistics including frequency, percentage, mean and standard deviation were used to describe study participants. To determine prevalence and predictive factors, a series of analytical tests and multinomial logistic regression were done. Adjusted odds ratios (AORs), with associated 95\% confidence intervals (CI) are reported. All statistical analyses were performed using version SPSS 22.0. P-values less than 0.05 were considered statistically significant.

\section{RESULTS}

In this study students' ages ranged from 15 to 18 years with a mean of $16.41 \pm 0.84$ years. A total of $324(44.4 \%)$ students were from Grade 1, while 272 $(37.3 \%)$ were from Grade 2 and 134 (18.4\%) were from Grade 3, at high school level. Regarding the educational status, 231 (31.6\%) students were in natural sciences, $201(27.5 \%)$ in technical fields, 168 $(23.0 \%)$ were in human sciences and $130(17.8 \%)$ in mathematical sciences. Most students, 228 (31.2\%), used a computer, and a total of 294 (40.3\%) used Internet for more than 7 hours. Table 1 presents demographic characteristics of the students.

According to WPS behaviors, 272 (37.3\%) were never WP smokers, 266 (36.4\%) former WP smokers and $192(26.3 \%)$ current WP smokers. The mean $( \pm \mathrm{SD})$ age at WPS initiation was $13.31 \pm 2.43$ years. A total of $531(72.7 \%)$ students had never experienced 
Table 1. Demographic characteristics of the study participants $(n=730)$

\begin{tabular}{|c|c|c|}
\hline Variables & Categories & Number $(\%)$ \\
\hline \multirow[t]{4}{*}{ Age (years) } & 15 & $96(13.2)$ \\
\hline & 16 & $310(42.5)$ \\
\hline & 17 & $253(34.7)$ \\
\hline & 18 & $71(9.7)$ \\
\hline \multirow[t]{4}{*}{ Major } & Human sciences & $168(23.0)$ \\
\hline & Natural sciences & $231(31.6)$ \\
\hline & Mathematics & $130(17.8)$ \\
\hline & Technical & $201(27.5)$ \\
\hline \multirow[t]{3}{*}{ High school grade } & Tenth & $324(44.4)$ \\
\hline & Eleventh & $272(37.3)$ \\
\hline & Twelfth & $134(18.4)$ \\
\hline \multirow[t]{4}{*}{ Father's education } & Illiteracy & $129(17.7)$ \\
\hline & Under the diploma & $225(30.8)$ \\
\hline & Diploma & $334(45.8)$ \\
\hline & College & $42(5.8)$ \\
\hline \multirow[t]{4}{*}{ Mother's education } & Illiteracy & $100(13.7)$ \\
\hline & Under the diploma & $211(28.9)$ \\
\hline & Diploma & $362(49.6)$ \\
\hline & College & $57(7.8)$ \\
\hline \multirow[t]{5}{*}{ Father's occupation } & Unemployed & $75(10.3)$ \\
\hline & Worker & $148(20.3)$ \\
\hline & Self-employed & $387(53.0)$ \\
\hline & Employee & $101(13.8)$ \\
\hline & Retired & $19(2.6)$ \\
\hline \multirow[t]{2}{*}{ Mother's occupation } & Housewife & $59(8.1)$ \\
\hline & Employed & $671(91.9)$ \\
\hline \multirow[t]{2}{*}{ Having own room } & Yes & $537(73.6)$ \\
\hline & No & $193(26.4)$ \\
\hline \multirow[t]{2}{*}{ Living (with) } & Both parents & $693(94.9)$ \\
\hline & Others & $37(5.1)$ \\
\hline
\end{tabular}

cigarette smoking. A total of 403 (55.2\%) students' friends did not smoke WP. Table 2 presents behavioral risk factors relating to WPS among the students.

Table 3 shows that being 17 years old $(\mathrm{AOR}=3.61$, 95\% CI: $1.53-8.52), 18$ years of age (AOR $=3.99,95 \%$ CI: 1.28-12.40), and studying in the technical fields (AOR $=2.70,95 \%$ CI: 1.49-4.90), were statistically significant predictors for current WPS. There was a trend (with reference group: 15 years old that never smoked WP) for increased likelihood of current smoking WP with increasing age; odds were 3.61 times higher for 17 years old $(p=0.003)$ and 3.99
Table 2. Behavioral risk factors characteristics among students $(\mathrm{n}=730)$

\begin{tabular}{llr} 
Varrables & \multicolumn{1}{c}{ Categories } & Number (\%) \\
WPS & Never & $272(37.3)$ \\
& Former & $266(36.4)$ \\
Work with computer & Current & $192(26.3)$ \\
& Low $(1-3 \mathrm{~h} / \mathrm{d})$ & $228(31.2)$ \\
& Medium $(3-7 \mathrm{~h} / \mathrm{d})$ & $226(31.0)$ \\
& High $(>7 \mathrm{~h} / \mathrm{d})$ & $159(21.8)$ \\
Internet usage & At all & $117(16.0)$ \\
& Low $(1-3 \mathrm{~h} / \mathrm{d})$ & $75(10.3)$ \\
& Medium $(3-7 \mathrm{~h} / \mathrm{d})$ & $172(23.6)$ \\
Ever cigarette & High $(>7 \mathrm{~h} / \mathrm{d})$ & $294(40.3)$ \\
smoking & Yes & $199(27.3)$ \\
& & \\
Current cigarette & Yes & $531(72.7)$ \\
smoking & & $97(13.3)$ \\
WP user friends & Yes & $633(86.7)$ \\
WP user family & Yes & $327(44.8)$ \\
& No & $403(55.2)$ \\
& No & $117(16.0)$ \\
& No & $613(84.0)$ \\
& &
\end{tabular}

WP: waterpipe, WPS: waterpipe smoking

times higher for 18 years old $(p=0.017)$ than for the reference group. Studying in the technical fields had odds of current WPS that were 2.70 higher than students in human sciences $(\mathrm{p}=0.001)$.

Table 4 shows that using Internet more than 7 hours per day (AOR=4.53, 95\% CI: 1.82-11.29), ever cigarette smoking (AOR=9.92, 95\% CI: 4.68-21.02), current cigarette smoking $(\mathrm{AOR}=8.41,95 \% \mathrm{CI}$ : $2.80-25.48)$ and family WPS (AOR $=7.22,95 \% \mathrm{CI}$ : 3.75-13.87) were statistically significant variables in relation to current WPS. Students who used the Internet more than 7 hours a day were 4.53 times more likely to be current smokers of WP compared to those who did not use the Internet and had never smoked WP $(p=0.001)$. There were also significant differences according to ever smoking cigarettes, currently smoking cigarettes and family member smoking WP. These were, respectively, 9.92, 8.41 and 7.22 times more likely to be currently smoking WP than never WPS (all $\mathrm{p}<0.001$ ).

Table 4 also shows that ever smoking cigarettes $(\mathrm{AOR}=5.14,95 \% \mathrm{CI}: 2.56-10.32)$, having WPS 
Table 3. Multinomial logistic regression: WPS and demographic factors (n=730)

\begin{tabular}{|c|c|c|c|c|c|c|c|}
\hline Characteristics & $\begin{array}{l}\text { Vever } \\
\text { UVPS } \\
(1 \mathrm{2}-272)(\%)\end{array}$ & $\begin{array}{l}\text { Former } \\
\text { WVPS } \\
(11-266)(\%)\end{array}$ & $\operatorname{AOR}\left(95^{\circ} \% \mathrm{CI}\right)$ & $p$ & $\begin{array}{l}\text { Current } \\
\text { WVS } \\
(n-192)(\%)\end{array}$ & IOR $\left(95^{\circ} \circ \mathrm{CI}\right)$ & p \\
\hline Age $^{\mathrm{a}}$ (years) & & & & 0.462 & & & 0.718 \\
\hline $15^{b}$ & $43(5.9)$ & $35(4.8)$ & 1.00 & - & $18(2.5)$ & 1.00 & - \\
\hline 16 & $127(17.4)$ & $110(15.1)$ & $1.00(0.58-1.73)$ & 0.988 & $73(10)$ & $1.40(0.72-2.74)$ & 0.315 \\
\hline 17 & $77(10.5)$ & $96(13.2)$ & $1.68(0.81-3.48)$ & 0.164 & $80(11)$ & $3.61(1.53-8.52)$ & $0.003^{* *}$ \\
\hline 18 & $25(3.4)$ & $25(3.4)$ & $1.84(0.67-5.02)$ & 0.236 & $21(2.9)$ & $3.99(1.28-12.40)$ & $0.017^{*}$ \\
\hline \multicolumn{8}{|l|}{ Major $^{a}$} \\
\hline Human sciences $^{b}$ & $64(8.8)$ & $72(9.9)$ & 1.00 & - & $32(4.4)$ & 1.00 & - \\
\hline Natural sciences & $92(12.6)$ & $92(12.6)$ & $0.69(0.41-1.17)$ & 0.172 & $47(6.4)$ & $0.68(0.36-1.30)$ & 0.248 \\
\hline Mathematics & $53(7.3)$ & $48(6.6)$ & $0.60(0.33-1.12)$ & 0.112 & $29(4)$ & $0.60(0.29-1.25)$ & 0.178 \\
\hline Technical & $63(8.6)$ & 54(7.4) & $0.64(0.37-1.09)$ & 0.104 & $84(11.5)$ & $2.70(1.49-4.90)$ & 0.001 \\
\hline \multicolumn{8}{|l|}{ High school grade ${ }^{a}$} \\
\hline Tenth $^{b}$ & $134(18.4)$ & 115 (15.8) & 1.00 & - & $75(10.3)$ & 1.00 & - \\
\hline Eleventh & $87(11.9)$ & $104(14.2)$ & $1.28(0.73-2.23)$ & 0.385 & $81(11.1)$ & $1.02(0.55-1.90)$ & 0.945 \\
\hline Twelfth & $51(7.0)$ & $47(6.4)$ & $0.70(0.32-1.55)$ & 0.386 & $36(4.9)$ & $0.82(0.34-1.99)$ & 0.673 \\
\hline \multicolumn{8}{|l|}{ Father's education ${ }^{a}$} \\
\hline Illiteracy ${ }^{b}$ & $12(1.6)$ & $16(2.2)$ & 1.00 & - & $14(1.9)$ & 1.00 & - \\
\hline Under the diploma & $129(17.7)$ & $130(17.8)$ & $0.62(0.25-1.50)$ & 0.290 & $75(10.3)$ & $0.50(0.19-1.29)$ & 0.154 \\
\hline Diploma & $80(11.0)$ & $80(11)$ & $0.70(0.27-1.84)$ & 0.475 & $65(8.9)$ & $0.84(0.30-2.33)$ & 0.736 \\
\hline College & $51(7.0)$ & $40(5.5)$ & $0.58(0.19-1.78)$ & 0.345 & $38(5.2)$ & $0.95(0.29-3.13)$ & 0.935 \\
\hline \multicolumn{8}{|l|}{ Mother's education $^{a}$} \\
\hline Illiteracy ${ }^{b}$ & $23(3.2)$ & $16(2.2)$ & 1.00 & - & $18(2.5)$ & 1.00 & - \\
\hline Under the diploma & 131 (17.9) & 145 (19.9) & $1.90(0.87-4.16)$ & 0.108 & $86(11.8)$ & $0.96(0.43-2.14)$ & 0.931 \\
\hline Diploma & $81(11.1)$ & $70(9.6)$ & $1.54(0.64-3.68)$ & 0.329 & $60(8.2)$ & $1.12(0.46-2.73)$ & 0.797 \\
\hline College & $37(5.1)$ & $35(4.8)$ & $2.20(0.75-6.43)$ & 0.150 & $28(3.8)$ & $1.24(0.40-3.80)$ & 0.708 \\
\hline \multicolumn{8}{|l|}{ Father's job ${ }^{\mathrm{a}}$} \\
\hline Unemployed ${ }^{b}$ & $6(0.8)$ & $8(1.1)$ & 1.00 & - & $5(0.7)$ & 1.00 & - \\
\hline Worker & $43(5.9)$ & $37(5.1)$ & $0.63(0.19-2.07)$ & 0.448 & $21(2.9)$ & $0.67(0.17-2.63)$ & 0.566 \\
\hline Self-employed & $125(17.1)$ & $153(21)$ & $0.87(0.28-2.77)$ & 0.822 & 109 (14.9) & $1.48(0.40-5.50)$ & 0.555 \\
\hline Employee & $65(8.9)$ & $48(6.6)$ & $0.54(0.16-1.85)$ & 0.326 & $35(4.8)$ & $0.74(0.18-3.02)$ & 0.676 \\
\hline Retired & $33(4.5)$ & $20(2.7)$ & $0.46(0.13-1.64)$ & 0.235 & $22(3)$ & $0.88(0.21-3.66)$ & 0.869 \\
\hline \multicolumn{8}{|l|}{ Mother's job ${ }^{\mathrm{a}}$} \\
\hline Housewife $^{b}$ & 247 (33.8) & $246(33.7)$ & 1.00 & - & $178(24.4)$ & 1.00 & - \\
\hline Employed & $25(3.4)$ & $20(2.7)$ & $0.85(0.39-1.81)$ & 0.671 & $14(1.9)$ & $0.76(0.32-1.78)$ & 0.535 \\
\hline \multicolumn{8}{|l|}{ Own room ${ }^{a}$} \\
\hline $\mathrm{No}^{\mathrm{b}}$ & $76(10.4)$ & $67(9.2)$ & 1.00 & - & $50(6.8)$ & 1.00 & - \\
\hline Yes & $196(26.8)$ & $199(27.3)$ & $1.17(0.77-1.76)$ & 0.454 & $142(19.5)$ & $1.19(0.75-1.90)$ & 0.445 \\
\hline \multicolumn{8}{|l|}{ Living (with) ${ }^{\mathrm{a}}$} \\
\hline Others $^{b}$ & $6(0.8)$ & $14(1.9)$ & 1.00 & - & $12(1.6)$ & 1.00 & - \\
\hline Both parents & $261(35.8)$ & $252(34.5)$ & $0.64(0.27-1.49)$ & 0.304 & $180(24.7)$ & $0.46(0.19-1.12)$ & 0.090 \\
\hline
\end{tabular}

Reference category: Never WPS. WPS: waterpipe smoking, Cl: confidence interval, AOR: adjusted odds ratio. a Categorical variables, b Reference group, ${ }^{*} p<0.05,{ }^{* *} p<0.01$, ${ }^{* * *} p<0.001$ 
Table 4. Multinomial logistic regression: WPS and behavioral risk factors (n=730)

\begin{tabular}{|c|c|c|c|c|c|c|c|}
\hline Characteristics & $\begin{array}{l}\text { vever } \\
\text { WPS } \\
(\text { (n 272) }(\%)\end{array}$ & $\begin{array}{l}\text { Former } \\
\text { UVPS } \\
(\text { n } 266)\left({ }_{0}\right)\end{array}$ & AOR $\left(95^{\circ} \% \mathrm{CI}\right)$ & $p$ & $\begin{array}{c}\text { Current } \\
\text { WPS } \\
(n-192)(\%)\end{array}$ & IOR $\left(95^{\circ} \circ \mathrm{CI}\right)$ & p \\
\hline Computer games $^{\mathrm{a}}$ & & & & 0.515 & & & 0.000 \\
\hline At all b & $86(11.8)$ & $80(11)$ & 1.00 & - & $62(85)$ & 1.00 & - \\
\hline Low (1-3 h/d) & $84(11.5)$ & $95(13)$ & $1.16(0.73-1.84)$ & 0.516 & $47(6.4)$ & $0.65(0.35-1.19)$ & 0.169 \\
\hline Moderate $(3-7 \mathrm{~h} / \mathrm{d})$ & $58(7.9)$ & $61(8.4)$ & $1.07(0.64-1.79)$ & 0.784 & $40(5.5)$ & $0.67(0.35-1.29)$ & 0.237 \\
\hline High (> 7h/d) & $44(6.0)$ & $30(4.1)$ & $0.64(0.35-1.18)$ & 0.159 & $43(5.4)$ & $0.58(0.28-1.18)$ & 0.136 \\
\hline \multicolumn{8}{|l|}{ Internet usage ${ }^{a}$} \\
\hline At all ${ }^{b}$ & $37(5.1)$ & $29(4)$ & 1.00 & - & $9(1.2)$ & 1.00 & - \\
\hline Low $(1-3 \mathrm{~h} / \mathrm{d})$ & $77(10.5)$ & $73(10)$ & $1.00(0.54-1.88)$ & 0.979 & $22(3)$ & $0.98(0.36-2.67)$ & 0.970 \\
\hline Moderate $(3-7 \mathrm{~h} / \mathrm{d})$ & $73(10.0)$ & 75 (10.3) & $1.08(0.58-2.04)$ & 0.791 & $41(5.6)$ & $2.12(0.81-5.52)$ & 0.124 \\
\hline High (> 7h/d) & 85 (11.6) & 89 (12.2) & $1.20(0.65-2.25)$ & 0.550 & $120(16.4)$ & $4.53(1.82-11.29)$ & $0.001^{* * *}$ \\
\hline \multicolumn{8}{|c|}{ Ever cigarette smoking } \\
\hline $\mathrm{No}^{\mathrm{b}}$ & $258(35.3)$ & $197(27)$ & 1.00 & - & $76(10.4)$ & 1.00 & - \\
\hline Yes & $14(1.9)$ & $69(9.5)$ & $5.14(2.56-10.32)$ & $0.000^{* * *}$ & $116(15.9)$ & $9.92(4.68-21.02)$ & $0.000^{* * *}$ \\
\hline \multicolumn{8}{|l|}{$\begin{array}{l}\text { Current cigarette } \\
\text { smoking }^{\text {a }}\end{array}$} \\
\hline $\mathrm{No}^{\mathrm{b}}$ & $267(36.6)$ & $239(32.7)$ & 1.00 & - & $127(17.4)$ & 1.00 & - \\
\hline Yes & $5(0.7)$ & $27(3.7)$ & $2.27(0.74-6.97)$ & 0.151 & $65(8.9)$ & $8.41(2.80-25.48)$ & $0.000^{* * *}$ \\
\hline \multicolumn{8}{|l|}{ WP user friends ${ }^{a}$} \\
\hline $\mathrm{No}^{\mathrm{b}}$ & $134(18.4)$ & $177(24.2)$ & 1.00 & - & $92(12.6)$ & 1.00 & - \\
\hline Yes & $138(18.9)$ & 89 (12.2) & $0.50(0.35-0.72)$ & $0.000^{* * *}$ & $100(13.7)$ & $0.88(0.55-1.40)$ & 0.599 \\
\hline \multicolumn{8}{|l|}{ WP user Familya } \\
\hline $\mathrm{No}^{\mathrm{b}}$ & $254(34.8)$ & $225(30.8)$ & 1.00 & - & $134(18.4)$ & 1.00 & - \\
\hline Yes & $18(2.5)$ & $41(5.6)$ & $2.55(1.40-4.64)$ & $0.002^{* *}$ & $58(7.9)$ & $7.22(3.75-13.87)$ & $0.000^{* * *}$ \\
\hline
\end{tabular}

friends $(\mathrm{AOR}=0.50,95 \%$ CI: $0.35-0.72)$ and having a WPS family member $(\mathrm{AOR}=2.55,95 \% \mathrm{CI}: 1.40$ 4.64) were significant variables in relation to former WPS. Based on this analysis, there were significant differences according to ever smoking cigarettes and having a WPS family member. These were, respectively, 5.14 and 2.55 times more likely to be former smokers of WP compared to never WPS. The odds of former WPS were also negatively associated with having friends who smoked WP; students who had friends that smoked WP were 0.50 times less likely to be former smokers of WP than those whose friends did not smoke WP $(\mathrm{p}<0.001)$.

\section{DISCUSSION}

The objective of the present study was to determine the role of sociodemographic factors associated with WPS among male adolescents in Hamadan city. This study has shown that former WPS (36.4\%) and current WPS prevalence (26.3\%) was quite high among high school students in Hamadan. These findings are in congruence with other studies $^{9,16}$. Prevalence estimates from our study are relatively low compared with studies carried out in some other Islamic countries. For instance, the prevalence of former WPS and current WPS among university students of Jordan was $61.1 \%$ and $42.7 \%$, respectively ${ }^{17}$, while ever WPS prevalence was $44.3 \%$ and current WPS prevalence was $22.1 \%$ in Lebanon ${ }^{18}$.

In the present study, the age range of the first experience with WPS was between 6 and 18 years, with a mean age of 13.31 years. The results of this part of the study were consistent with those of similar studies. For example in Iran, the mean ages for initiation of WPS that were found ranged from 13.39 to 13.80 years $^{9,19,20}$. The results of our study revealed that there is a need to plan and implement effective interventions to prevent tendencies for 
substance abuse in adolescence.

According to our findings, WPS was associated with the age of students. In this regard, increased age of students added to the chance of WPS. These findings are in congruence with other studies on this topic $^{9,18,21-24}$. It seems that early WPS at a younger age leads to increased addiction to WPS in older ages, resulting in students continuing WPS. Our observation that studying in technical fields resulted in higher odds of WPS than those in the human sciences might indicate differences in understanding of the health risks of hookah smoking and different social norms across disciplines. Similar findings have also been reported elsewhere ${ }^{25}$.

This study has shown that students who use Internet more than 7 hours a day were likely to be current WPS. Studies have shown that Internet addiction is related to tobacco smoking ${ }^{26,27}$. Those addicted to the Internet may conceivably be bored, tired, shy, depressed and suffer from other types of addiction, such as cigarette smoking ${ }^{28}$. Students that reported lifetime (ever) cigarette smoking were significantly more likely to also report former and current WPS than non-smokers of cigarettes. These findings are consistent with previous research ${ }^{9,29-32}$. A possible explanation might be that WPS is being used by youth as an alternative to cigarette smoking among those who want to quit cigarette smoking; it could also be that WPS leads to other forms of tobacco smoking. Also, we found that current cigarette smokers were significantly more likely to be current WPS than others. The results of this part of the study were consistent with the findings of similar studies ${ }^{24,33}$. Perceiving WP as less harmful than cigarettes was positively associated with its use, suggesting that students may be uncertain about the harms associated with WPS relative to cigarette smoking. This misperception was more prevalent among young adults and in never smokers.

Although, previous studies ${ }^{7,10,31,34}$ have shown that having friends as users of WP is related to WPS, our study found that having friends as users of WP was inversely associated with former WPS. The reason for this might be that students who have used WP in the past have had unpleasant health experiences of the negative effects of WPS. The sharing of this unpleasant experience with friends who have not yet smoked hookah might have played a protective role in preventing initiation.

Results from our study show that social influence from family was significantly associated with students' former and current WPS. There are some studies with findings that are similar to our result ${ }^{10,35,36}$. Family members might own a WP for home use ${ }^{37}$ and hold social gatherings at home to smoke $\mathrm{WP}^{38}$. In order to reduce WPS prevalence, public health interventions need not only to target adolescents but also their family members' risk perceptions, attitudes and behaviors regarding WPS.

This study has some limitations. First, the crosssectional design used in this study is restricted in establishing cause-effect relationships. Being cross-sectional it provides only a snap-shot in time and does not provide guidance on time sequence. Second, this study was restricted to students in Grades 10-12 in high schools of Hamadan, which limits its generalizability. Third, self-reported data could be prone to bias in reporting (i.e. under reporting or over reporting). Ideally, biochemical testing should have been done, but our results were not biochemically confirmed. Fourth, because of challenges getting permission to enter the girls' high schools, the current study was restricted to only male high schools. These findings may therefore not apply to all Iranian adolescents.

\section{CONCLUSIONS}

Our study shows that WPS prevalence is high among male high school students in Hamadan. There is a need to design interventional studies to increase students', friends' and parents' knowledge about the harms of WPS and cigarette smoking, to encourage behavior change in this regard, and to put in place restrictive policies for curtailing adolescents' access to WP and tobacco. In addition, our findings require public health campaigns to access and educate students, teachers and schools, to inform them of the growing understanding of the health effects of WPS.

\section{REFERENCES}

1. Abdullah P, Costanian C, Khanlou N, Tamim H. Prevalence and characteristics of water-pipe smoking in Canada: results from the Canadian Tobacco Use Monitoring Survey. Public Health. 2017;148(Supplement G):102108. doi:10.1016/j.puhe.2017.03.007

2. Maziak W. The global epidemic of waterpipe smoking. Addictive Behaviors. 2011;36(1-2):1-5. 
doi:10.1016/j.addbeh.2010.08.030

3. El-Zaatari ZM, Chami HA, Zaatari GS. Health effects associated with waterpipe smoking. Tobacco Control. 2015;24(Suppl 1):i31-i43. doi:10.1136/tobaccocontrol-2014-051908

4. Mehboudi MB, Nabipour I, Vahdat K, et al. Inverse association between cigarette and water pipe smoking and hypertension in an elderly population in Iran: Bushehr elderly health programme. Journal of Human Hypertension. 2017;31(12):821-825. doi:10.1038/jhh.2017.64

5. WHO Study Group on Tobacco Product Regulation. Waterpipe Tobacco Smoking: Health Effects, Research Needs and Recommended Actions for Regulators. 2nd ed. Geneva, Switzerland: World Health Organization Document Production Services; 2015. http://apps.who. int/iris/bitstream/10665/161991/1/9789241508469_ eng.pdf. Accessed January 23, 2018.

6. Ziaei R, Mohammadi R, Dastgiri S, et al. The Prevalence, Attitudes, and Correlates of Waterpipe Smoking Among High School Students in Iran: a CrossSectional Study. Int J Behav Med. 2016;23(6):686-696. doi:10.1007/s12529-016-9555-x

7. Swedish Public Health Authorities. Water pipe. Smoking with adverse effects. http://www.folkhalsomyndigheten. se/pagefiles/12825/ Vattenpipa-rokning-med-skadligaeffekter_NY.pdf Published 2013. Accessed December 10, 2014.

8. Czoli CD, Leatherdale ST, Rynard V. Bidi and Hookah Use Among Canadian Youth: Findings From the 2010 Canadian Youth Smoking Survey. Prev Chronic Dis. 2013;10:E73. doi:10.5888/pcd10.120290

9. Bashirian S, Barati M, Mohammadi Y, Mostafaei H. Factors Associated with Hookah Use among Male High School Students: The Role of Demographic Characteristics and Hookah User and Non-User Prototypes. Journal of Research in Health Sciences. 2016;16(4):217-223

10. Jawad M, Nakkash RT, Mahfoud Z, Bteddini D, Haddad P, Afifi RA. Parental smoking and exposure to environmental tobacco smoke are associated with waterpipe smoking among youth: results from a national survey in Lebanon. Public Health. 2015;129(4):370376. doi:10.1016/j.puhe.2015.01.011

11. Maziak W, Eissenberg T, Ward KD. Patterns of waterpipe use and dependence: implications for intervention development. Pharmacology Biochemistry and Behavior. 2005;80(1):173-179. doi: 10.1016/j.pbb.2004.10.026

12. Afifi R, Khalil J, Fouad F, et al. Social norms and attitudes linked to waterpipe use in the Eastern Mediterranean Region. Social Science \& Medicine. 2013;98:125-134. doi:10.1016/j.socscimed.2013.09.007

13. Fakhari A, Mohammadpoorasl A, Nedjat S, Sharif Hosseini M, Fotouhi A. Hookah smoking in high school students and its determinants in Iran: a longitudinal study. American Journal of Men's Health. 2015;9(3):186-192. doi:10.1177/1557988314535236

14. Mohammad-Alizadeh-Charandabi S, Mirghafourvand M, Tavananezhad N, Karkhaneh M. Prevalence of cigarette and water pipe smoking and their predictors among Iranian adolescents. International Journal of Adolescent Medicine and Health. 2015;27(3):291-298. doi:10.1515/ijamh-2014-0028

15. M Barati, A Heidarnia, S Niknami, Allahverdipour H. Factors Associated With Tobacco Smoking Among Male Adolescents: the Role of Psychologic, Behavioral, and Demographic Risk Factors. Avicenna J Neuro Psych Physio. 2015;2(1):e27152. doi:10.17795/ajnpp-27152

16. Momenan A, Etemadi A, Azizi F. Pattern of hookah use among teenager students: a cross-sectional study in Tehran. Payesh. 2007;6(2):135-144.

17. Azab M, Khabour OF, Alkaraki AK, Eissenberg T, Alzoubi KH, Primack BA. Water pipe tobacco smoking among university students in Jordan. Nicotine Tob Res. 2010;12(6):606-612. doi:10.1093/ntr/ntq055

18. Jawad M, Nakkash RT, Mahfoud Z, Bteddini D, Haddad P, Afifi RA. Parental smoking and exposure to environmental tobacco smoke are associated with waterpipe smoking among youth: results from a national survey in Lebanon. Public Health. 2015;129(4):370376. doi:10.1016/j.puhe.2015.01.011

19. Abedini S, MorowatiSharifabad M, Chaleshgar Kordasiabi M, Ghanbarnejad A. Predictors of nonhookah smoking among high-school students based on prototype/willingness model. Health Promot Perspect. 2014;4(1):46-53. doi:10.5681/hpp.2014.006

20. Barati M, Allahverdipour H, Hidarnia A, Niknami S. Predicting tobacco smoking among male adolescents in Hamadan City, west of Iran in 2014: an application of the prototype willingness model. Journal of Research in Health Sciences. 2015;15(2):113-118.

21. Dehdari T, Jafari A, Joveyni H. Students' perspectives in Tehran University of Medical Sciences about factors affecting smoking hookah. Razi Journal of Medical Sciences. 2012;19(95):17-24.

22. Joveyni H, Gohari MR, Gharibnavaz H. Attitudes, subjective norms, and perceived behavioral control of college students about hookah smoking cessation. Journal of Health System Research. 2013;8(7):13111321.

23. Kelishadi R, Heshmat R, Shahsanai A, et al. Determinants of tobacco and hookah smoking in a nationally representative sample of Iranian children and adolescents: The Caspian-IV Study. Iran Red Crescent Med J. 2016;18(8):e31099. doi:10.5812/ircmj.31099

24. Majeed BA, Sterling KL, Weaver SR, Pechacek TF, Eriksen MP. Prevalence and harm perceptions of hookah smoking among U.S. adults, 2014-2015. Addictive Behaviors. 2017;69(Supplement G):78-86. doi:10.1016/j.addbeh.2017.01.032 
25. Primack BA, Walsh M, Bryce C, Eissenberg T. Waterpipe tobacco smoking among middle and high school students in Arizona. Pediatrics. 2009;123(2):e282-e288.

26. Jiang Q, Huang X, Tao R. Examining Factors Influencing Internet Addiction and Adolescent Risk Behaviors Among Excessive Internet Users. Health Communication. 2017;29:1-11. doi:10.1080/10410236.2017.1358241

27. Seyrek S, Cop E, Sinir H, Ugurlu M, Senel S. Factors associated with Internet addiction: Cross-sectional study of Turkish adolescents. Pediatrics International. 2017;59(2):218-222. doi: 10.1111/ped.13117

28. Prasanna G, Lai L. Some Observations On Internet Addiction Disorder Research. Journal of Information Systems Education. 2012;11(3-4):97-107.

29. Villanti AC, Cobb CO, Cohn AM, Williams VF, Rath JM. Correlates of Hookah Use and Predictors of Hookah Trial in U.S. Young Adults. Am J Prev Med. 2015;48(6):742746. doi:10.1016/j.amepre.2015.01.010

30. Sutfin EL, McCoy TP, Reboussin BA, Wagoner KG, Spangler J, Wolfson M. Prevalence and correlates of waterpipe tobacco smoking by college students in North Carolina. Drug and Alcohol Dependence. 2011;115:131136. doi:10.1016/j.drugalcdep.2011.01.018

31. Jaber R, Madhivanan P, Khader Y, Mzayek F, Ward KD, Maziak W. Predictors of waterpipe smoking progression among youth in Irbid,Jordan: A longitudinal study (2008-2011). Drug and Alcohol Dependence. 2015;153: 265-270. doi:10.1016/j.drugalcdep.2015.05.008

32. McKelvey K, Attonito J, Madhivanan P, et al. Determinants of waterpipe smoking initiation among school childrenin Irbid, Jordan: A 4-year longitudinal analysis. Drug and Alcohol Dependence. 2014;142:307313. doi:10.1016/j.drugalcdep.2014.06.038

33. Huang LL, Sutfin EL, Kowitt S, Patel T, Ranney L, Goldstein AO. Trends and corrolations of hookah use among high school students in North Carolina. North Carolina Medical Journal. 2017;78(3):149-155. doi:10.18043/ncm.78.3.149

34. Kotecha S, Jawad M, Iliffe S. Knowledge, attitudes and beliefs towards waterpipe tobacco smoking and electronic shisha (e-shisha) among young adults in London: a qualitative analysis. Primary Health Care Research \& Development. 2016;17(2):166-174. doi:10.1017/S1463423615000237

35. Abbasi-Ghahramanloo A, Rahimi-Movaghar A, Zeraati H, Safiri S, Fotouhi A. Prevalence of Hookah Smoking and Its Related Factors Among Students of Tehran University of Medical Sciences, 2012 - 2013. Iranian Journal of Psychiatry and Behavioral Sciences. 2016;10(2):e4551. doi:10.17795/ijpbs-4551

36. Amin TT, Amr MA, Zaza BO, Kaliyadan F. Predictors of waterpipe smoking among secondary school adolescents in Al Hassa, Saudi Arabia. International Journal of Behavioural Medicine. 2012;19(3):335-324. doi:10.1007/s12529-011-9169-2

37. Griffiths MA, Harmon TR, Gilly MC. Hubble Bubble Trouble: The Need for Education About and Regulation of Hookah Smoking. Journal of Public Policy \& Marketing. 2011;30(1):119-132. doi:10.1509/jppm.30.1.119

38. Jamil H, Janisse J, Elsouhag D, Fakhouri M, Arnetz JE, Arnetz BB. Do household smoking behaviors constitute a risk factor for hookah use? Nicotine Tob Res. 2011;13(5):384-388. doi: 10.1093/ntr/ntq249
ACKNOWLEDGEMENTS

We thank our participants, and the staff of Education District 1 and 2 of Hamadan city.

CONFLICTS OF INTEREST

Authors have completed and submitted the ICMJE Form for Disclosure of Potential Conflicts of Interest and none was reported.

FUNDING

This study has been supported by Hamadan University of Medical Sciences, Grant (960115134).

PROVENANCE AND PEER REVIEW Not commissioned; externally peer reviewed. 